\title{
Algoritma Triple Exponential Smoothing Untuk Prediksi Trend Turis Pariwisata Jatim Park Batu saat Pandemi Covid-19
}

\author{
Safor Madianto ${ }^{1}$, Ema Utami ${ }^{2}$, Anggit Dwi Hartanto ${ }^{3}$ \\ 1,2,3 Magister Teknik Informatika, Universitas Amikom Yogyakarta \\ safor.1292@students.amikom.ac.id ${ }^{1}$, ema.u@ amikom.ac.id ${ }^{2}$, anggit@amikom.ac.id ${ }^{3}$
}

\section{Article Info \\ Article history: \\ Received 05-07-2021 \\ Revised 13-07-2021 \\ Accepted 19-07-2021}

Keyword:

Triple Exponential Smoothing,

Prediction,

Holt Winters,

Forecasting,

Tourism,

Jatim Park.

\begin{abstract}
The level of tourist arrivals in 2021, both local and foreign to Indonesian tourism, will drop significantly. The COVID-19 pandemic is one of the causes of this loss. In the last 1 year, the level of tourism has decreased drastically due to this pandemic. The impact for a country is an economic recession, Singapore is a country that is experiencing a recession that is quite severe up to $-40 \%$, a country that also depends on tourism, one of them. Jatim Park, Batu is a family recreation park and study tour in Batu, East Java. Jatim Park is a fairly well-known tourist attraction in East Java. The uncertainty of the number of tourists each month affects the operational management of Jatim Park in making every decision, both technical and strategic decisions. The researcher proposes to use the Triple Exponential Smoothing algorithm of the Holt-Winters model, which is a predictive algorithm that can consider trends and seasonal factors. The method of measuring accuracy uses the MAPE (Mean Absolute Percentage Error) method. The test was carried out by initiating the alpha, beta and gamma parameters 30 times and obtained an average of $9 \%$.
\end{abstract}

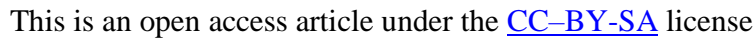

\section{Pendahuluan}

Tingkat kunjungan pariwisata ditahun 2021 baik lokal maupun mancanegara terhadap pariwisata Indonesia mengalami penurunan drastis. Pandemi COVID-19 menjadi salah satu sebab dari adanya kerugian tersebut. Berdasarkan data yang diperoleh melalui website Kementrian Pariwisata dan Ekonomi Kreatif, kunjungan wisatawan mancanegara pada Februari 2021 melalui seluruh pintu masuk mengalami penurunan sebesar $86.59 \%$ sebesar 117.000. Penurunan ini dirasakan sangat signifikan, karena apabila dibandingkan dengan Februari 2020 yang berjumlah 872.765 [1].

Dalam 1 tahun terakhir ini, tingkat pariwisata menurun drastis dikarenakan pandemi ini. Dampak terhadap sebuah negara adalah resesi ekonomi, Singapura adalah negara yang mengalami resesi cukup parah hingga $-40 \%$, negara adalah negara yang juga bergantung salah satunya pada pariwisata [2].

Jatim Park Batu adalah sebuah pariwisata taman belajar dan tempat rekreasi keluarga di Batu, Jawa Timur. Jatim Park merupakan tergolong pariwisata yang terkenal di Jawa Timur, terdapat beberapa pilihan tidak hanya 1 tempat Jatim Park saja, namun ada 3 objek pariwisata Jatim Park yang memiliki objek rekreasi masing - masing. Pandemi COVID-19 yang terjadi pada akhir tahun 2019 turut serta mempengaruhi jumlah turis baik lokal maupun mancanegara dalam berkunjung ke Jatim Park.

Ketidakpastian jumlah turis tiap bulannya mempengaruhi manajemen operasional Jatim Park dalam melakukan setiap pengambilan keputusan, baik keputusan yang bersifat teknis maupun strategis. Salah satu teknik dalam Data Mining, yaitu prediksi dapat digunakan untuk memprediksi dan memvisualisasikan trend pengunjung Jatim Park. Dengan memprediksi 3 periode bulan ke depan kemudian memvisualisasikan trendnya ke dalam grafik, akan dapat diketahui trend pengunjung apakah meningkat atau menurun. Penulis telah melakukan pengambilan data dan memvisualisasikan ke dalam plot grafik untuk tahun 2019 hingga 2020 selama rentang 1 tahun 10 bulan dan mendapatkan gambaran seperti ditunjukkan pada gambar 1 .

Pada grafik tren yang ditunjukkan pada gambar 1 , terlihat pola data fluktuatif, namun dapat dianalisa bahwa pada bulan- 
bulan tertentu yang sama, terjadi penurunan atau kenaikan, berdasarkan grafik tersebut, juga dapat disimpulkan trendnya adalah menurun.

Pola data fluktuatif yang memiliki trend menurun tersebut merupakan dasar peneliti menentukan algoritma seperti apa yang akan dipilih, peneliti memerlukan algoritma prediksi Time Series yang mampu menghandle data trend dan musiman [3], merujuk kepada penelitian prediksi penjualan pulsa elektrik yang telah dilakukan sebelumnya, dimana pola dataset yang digambarkan fluktuatif dengan trend naik dan memiliki kecenderungan musiman, maka peneliti tersebut memilih menggunakan algoritma Triple Exponential Smoothing.

Berdasarkan pola data dan grafik tersebut, penulis mengusulkan untuk menggunakan algoritma Triple Exponential Smoothing, model Holt Winters, dimana algoritma ini adalah tergolong algoritma prediksi yang dapat mempertimbangkan faktor trend dan musiman. Algoritma tersebut akan melakukan prediksi dengan melakukan pemulusan data terlebih dahulu, Dataset yang digunakan adalah dalam jangka waktu rentang 1 tahun 10 bulan (ditunjukkan pada gambar 1).

Penggunaan dataset yang terhitung cukup panjang, akan mendukung proses prediksi algoritma Triple Exponential Smoothing, dikarenakan algoritma ini memiliki karakteristik, hasil prediksi akan semakin baik apabila data pemulusan yang digunakan semakin banyak. 3 parameter di awal proses prediksi yang harus diatur secara acak yaitu parameter Alfa ( $\alpha$ ), Beta ( $\beta$ ) dan Gamma ( $\gamma$ ), akan sangat mempengaruhi hasil proses prediksi, dimana ditunjukkan pada akurasi hasil prediksi. Berdasarkan karakteristik algoritma tersebut maka nantinya, metode eksperimennya sendiri yaitu, peneliti akan menguji coba 30 data acak 3 parameter untuk diujicobakan ke algoritma Triple Exponential Smoothing. Metode pengukuran akurasi menggunakan metode (Mean Absolute Percetage Error) MAPE.

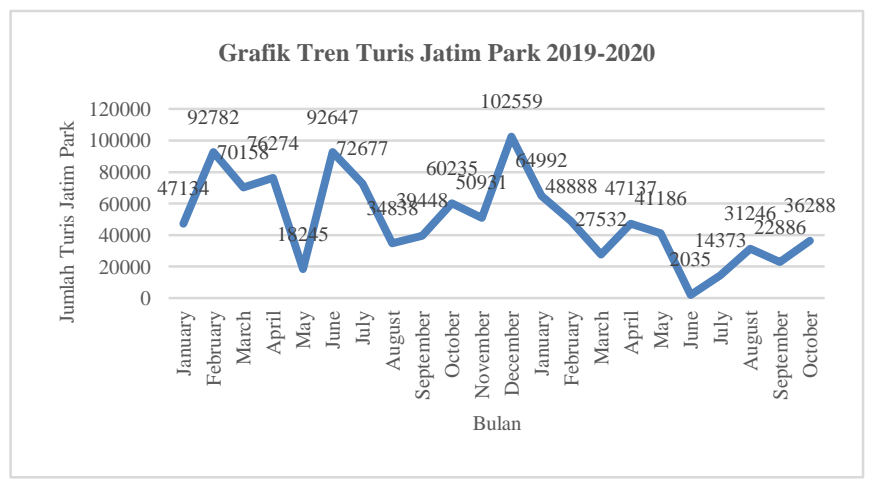

Gambar 1. Grafik Tren Turis Jatim Park 2019-2020

Algoritma Triple Exponential Smoothing - Holt Winters adalah algoritma konvensional di topik prediksi atau forecasting, algoritma ini sudah lebih sering diterapkan pada bidang ilmu Statistik dan Ekonomi dalam mengamati dan menganalisa trend data. Penerapannya di bidang Computer Science, membuat algoritma ini semakin berkembang dan terus menerus diteliti. Peneliti menggunakan 5 rujukan refrensi yang dijadikan sebagai dasar acuan menganalisa trend data turis Jatim Park menggunakan algoritma tersebut, yaitu penerapan algoritma Triple Exponential Smoothing untuk prediksi penjualan alat Kesehatan [4] dimana dalam penelitian tersebut dilakukan prediksi jumlah penjualan alat kesehatan dimasa yang akan datang. Jumlah permintaan yang berubah - ubah akan mempengaruhi jumlah stok yang harus disiapkan digudang.

Selanjutnya adalah Prediksi Jumlah Kebutuhan Pemakaian Air Menggunakan Metode Exponential Smoothing [5], dimana dalam penelitian tersebut dilakukan prediksi mengenai kebutuhan pemakaian air minum pada PDAM Kota Malang, jumlah pemakaian air yang selalu berubah - ubah tiap bulannya akan mempengaruhi stok debit air yang harus disiapkan oleh PDAM Kota Malang.

Penelitian yang selanjutnya Implementasi metode Triple Exponential Smoothing Dalam Peramalan Penjualan Pulsa Elektrik [3] dimana dalam penelitian tersebut dilakukan prediksi mengenai penjualan pulsa elektrik. Jumlah permintaan pulsa elektrik tiap bulan dengan operator yang berbeda akan mempengaruhi stok saldo pulsa elektrik owner counternya.

Melihat banyaknya penelitian variatif tentang prediksi dengan menggunakan algoritma Triple Exponential Smoothing ini, maka penulis terus menggali algoritma tersebut dan menemukan bahwa algoritma Triple Exponential Smoothing merupakan model algoritma prediksi Exponential Smoothing yang memiliki varian lainnya dilihat dari jumlah parameter yang digunakan, model Exponential Smoothing lainnya yaitu Single Exponential Smoothing dan Double Exponential Smoothing [6][7]. Model lainnya ada Moving Average, dimana model ini terdapat algoritma - algoritma seperti Simple Moving Average, Weighted Moving Average [8].

Hasil dari prediksi model - model tersebut nantinya akan di uji keakurasiannya. Seperti yang telah dijelaskan di paragraf sebelumnya bahwa metode pengukuran akurasi yang akan digunakan pada penelitian ini adalah metode MAPE, namun pada rujukan - rujukan lainnya, metode pengukuran akurasi yang digunakan contohnya seperti MSE (Mean Square Error) dimana metode ini juga sama dengan MAPE, jika perbedaannya metode MSE digunakan untuk mengevaluasi hasil prediksi, MAPE digunakan untuk digunakan untuk mencari selisih antara data sebenarnya dengan data hasil prediksi, dimana dapat divisualisasikan dalam bentuk prosentase [9].

Berdasarkan dasar acuan rujukan - rujukan tersebut, maka penulis memilih menggunakan algoritma Triple Exponential Smoothing - Holt Winters pada penelitian ini. Algoritma prediksi ini dapat dikatakan powerful dan dapat dikombinasikan dengan algoritma lain, misal seperti kombinasi algoritma Triple Exponential Smoothing dan Trend Moment, dimana dataset yang digunakan untuk 
prediksi terdapat Data Missing, sehingga peneliti wajib membuang atau melakukan estimasi (untuk data numerik) pada Data Missing tersebut. Estimasinya dilakukan dengan menggunakan algoritma Trend Moment. Contoh lainnya adalah kombinasi algoritma Triple Exponential Smoothing dan FP-Growth dimana dalam kasus penjualan, algoritma FPGrowth digunakan untuk mengetahui perilaku pola konsumen agar dapat digunakan untuk bahan pengambilan keputusan pada penyusunan barang sedangkan algoritma Triple Exponential Smoothing digunakan untuk memanajamen dan mengatur stok barang [10].

Berdasarkan dasar alasan tersebut dan disertai rujukan karya ilmiah yang relevan dan setopik, peneliti memilih untuk menggunakan algoritma Triple Exponential Smoothing Holt Winters sebagai algoritma yang akan digunakan dalam penelitian ini.

\section{METODE PENELITIAN}

Penulis mendapatkan dataset turis wisata Jatim Park Batu secara primer dengan pihak pengelola Jatim Park Batu, dataset berupa file Microsoft Excel yang ditunjukkan pada gambar 2 .

\begin{tabular}{|c|c|c|c|}
\hline \multirow{2}{*}{\multicolumn{2}{|c|}{$\begin{array}{l}\text { JATIM PARK GROUP } \\
\text { DATA PENGUNJUNG }\end{array}$}} & \multicolumn{2}{|c|}{ JATIM PARK GROUP } \\
\hline & DATA PENGUNJUNG & \multicolumn{2}{|c|}{ DATA PENGUNJUNG } \\
\hline 2019 & & 2020 & \\
\hline Bulan & JTP 2 & Bulan & JTP 2 \\
\hline Januari & 47.134 & Januari & 64.992 \\
\hline Februari & 92.782 & Februari & 48.888 \\
\hline Maret & 70.158 & Maret & 27.532 \\
\hline April & 76.274 & April & - \\
\hline Mei & 18.245 & Mei & - \\
\hline Juni & 92.647 & Juni & 2.035 \\
\hline Juli & 72.677 & Juli & 14.373 \\
\hline Agustus & 34.838 & Agustus & 31.246 \\
\hline September & 39.448 & September & 22.886 \\
\hline Oktober & 60.235 & Oktober & 36.288 \\
\hline November & 50.931 & November & \\
\hline Desember & 102.559 & Desember & \\
\hline TOTAL & 757.928 & TOTAL & 248.240 \\
\hline
\end{tabular}

Gambar 2. Dataset Turis Pariwisata Jatim Park Baru 2019

Tabel 1 menunjukkan langkah - langkah perhitungan dan contohnya algoritma Triple Exponential Smoothing - Holt Winters.
TABEL I

LANGKAH - LANGKAH ALGORITMA TRIPLE EXPONENTIAL SMOOTHING HOLT WINTERS

\begin{tabular}{|c|c|}
\hline No & Langkah Algoritma \\
\hline 1 & $\begin{array}{l}\text { Mengambil data aktual } 3 \text { baris pertama, kemudian } \\
\text { membuat rata-ratanya, dimana nantinya digunakan } \\
\text { sebagai nilai awal level dan trend pertama kali }\end{array}$ \\
\hline 2 & $\begin{array}{l}\text { Menghitung nilai seasonal baris pertama, membagi data } \\
\text { aktual dengan nilai rata-rata data aktual, dengan cara yang } \\
\text { sama dicari baris seasonal } 2 \text { dan } 3\end{array}$ \\
\hline 3 & $\begin{array}{l}\text { Menentukan parameter alfa, beta dan gamma secara acak: } \\
\alpha=0.5 \\
\beta=0.6 \\
\gamma=0.9\end{array}$ \\
\hline 4 & $\begin{array}{l}\text { Melakukan perhitungan mencari level baris ke } 4: \\
\alpha^{*}\left(\text { dataAktual/seasonal }_{n-3}\right)+(1-\alpha)^{*}\left(\text { level }_{n-1}+\text { trend }_{n-1}\right)\end{array}$ \\
\hline 5 & $\begin{array}{l}\text { Melakukan perhitungan mencari trend baris ke } 4 \text { : } \\
\beta^{*}\left(\text { levelAktual-level }_{n-1}\right)+(1-\beta)^{*} \text { trend }_{n-1}\end{array}$ \\
\hline 6 & $\begin{array}{l}\text { Melakukan perhitungan mencari seasonal baris ke } 4 \text { : } \\
\gamma^{*}(\text { dataAktual/levelAktual })+(1-\gamma) * \text { seasonal }_{n-3}\end{array}$ \\
\hline 7 & $\begin{array}{l}\text { Melakukan perhitungan mencari prediksi baris ke } 4 \text { : } \\
\left(\text { level }_{n-1}+\left(1 \text { trend }_{n-1}\right)\right)^{*} \text { seasonal }_{n-3}\end{array}$ \\
\hline 8 & Round(hasilPrediksi) \\
\hline 9 & $\begin{array}{l}\text { Melakukan perhitungan mencari MAPE baris ke } 4 \text { : } \\
\mid(((\text { dataAktual- } \\
\text { prediksiAktualRound)/dataAktual)/bykDataAktual }) \mid\end{array}$ \\
\hline 10 & $\begin{array}{l}\text { Dengan cara yang sama dicari baris prediksi yang } \\
\text { selanjutnya }\end{array}$ \\
\hline 11 & $\begin{array}{l}\text { Menghitung MAPE setiap baris prediksi } \\
\text { Menghitung MAPE rata-rata keseluruhan = Total Mape } \\
\text { keseluruhan/Banyak Mape yang dihitung }\end{array}$ \\
\hline
\end{tabular}

Tabel 1 menunjukkan langkah - langkah perhitungan algoritma Triple Exponential Smoothing - Holt Winters, dimana untuk contohnya dimulai dari:

- Mengambil dan melakukan rata - rata data aktual 3 baris pertama yaitu 47.134, 92.782 dan 70.158 (berdasarkan gambar 2 tahun 2019) dan hasilnya digunakan sebagai inisialisasi level dan trend baris ke 3, sedangkan baris 1 dan 2 kosong, dimana hasilnya 70.025

- Menghitung seasonal baris pertama dengan cara membagi data aktual dengan 70.025, dimana 47.134/70.025 hasilnya 0.6731 , dan seterusnya

- Menentukan inisialisasi parameter alfa beta dan gamma secara acak, misalnya $\alpha=0.5, \beta=0.6$ dan $\gamma=0.9$

- Melakukan perhitungan mencari level baris ke 4 : $0.5 *(76.274 / 0,6731)+(1-0.5) *(70.025-70.025) \quad$ dimana hasilnya 56658,7

- Melakukan perhitungan mencari trend baris ke 4 : $0.6 *(56658.7-70.025)+(1-0.6) * 70.025$ dimana hasilnya 61963.205

- Melakukan perhitungan mencari seasonal baris ke 4 : $0.9 *(76.274 / 56658.7)+(1-0.9) * 0.6731$ dimana hasilnya 1,2789

- Melakukan perhitungan mencari prediksi baris ke 4 : 
$(70.025+(1 * 70.025)) * 0.6731$ dimana hasilnya $94.267,21$ dan dilakukan pembulatan maka didapatkan 94.267

- Melakukan perhitungan mencari MAPE baris ke 4 : $|(((76.274-94.267) / 76.274) / 22)|$ dimana hasilnya 0,010722705 , apabila diprosentasekan didapatkan $1 \%$

- Kemudian dilakukan perhitungan mencari level, trend, seasonal, prediksi, pembulatan prediksinya dan MAPEnya seterusnya hingga periode yang diinginkan, setelah itu dilakukan rata - rata perhitungan semua MAPEnya dengan menjumlah angka desimal MAPEnya lalu dibagi banyak datanya

Secara alur algoritma yang menyatakan keseluruhan peta motode penelitian ditunjukkan seperti gambar no 3 .

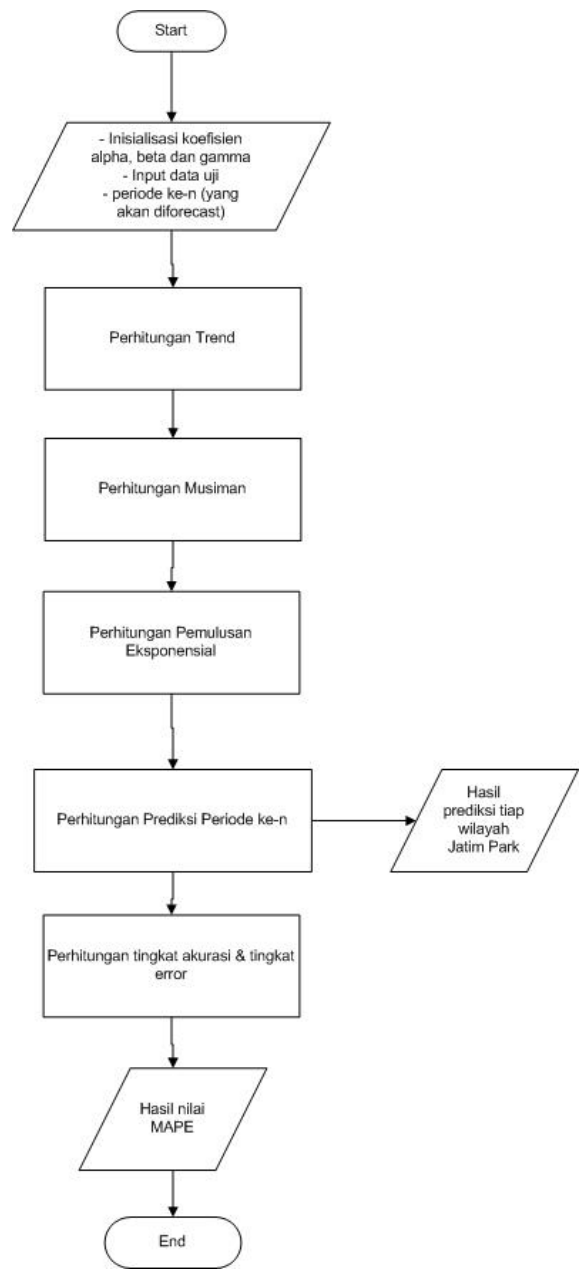

Gambar 3. Alur algoritma Triple Exponential Smoothing - Holt Winters dari awal hingga akhir

\section{HASIL DAN PEMBAHASAN}

Untuk menguji algoritma Triple Exponential Smoothing Holt Winters akan diambil secara random inisiasi 3 parameter alfa, beta dan gamma. 3 parameter tersebut yang akan digunakan dalam melakukan per hitungan pemulusan algoritma Triple Exponential Smoothing - Holt Winters pada bagian seasonal, level dan trend.

Untuk pengujian algoritma Triple Exponential Smoothing - Holt Winters dilakukan uji coba inisiasi parameter alfa beta dan gamma secara acak sebanyak 30 kali dengan bantuan tools aplikasi yang sudah dikembangkan.

TABEL II

PERCobaAn Algoritma TRIPLE EXPONENTIAL SMOOTHING - HOLT WINTERS SEBANYAK 30 KALI

\begin{tabular}{|c|c|c|c|c|}
\hline No & Alfa & Beta & Gamma & MAPE \\
\hline 1 & 0,8 & 0,6 & 0,5 & $10 \%$ \\
\hline 2 & 0,5 & 0,2 & 0,2 & $9 \%$ \\
\hline 3 & 0,1 & 0,5 & 0,5 & $11 \%$ \\
\hline 4 & 0,1 & 0,6 & 0,3 & $10 \%$ \\
\hline 5 & 0,1 & 0,2 & 0,3 & $24 \%$ \\
\hline 6 & 0,8 & 0,4 & 0,6 & $9 \%$ \\
\hline 7 & 0,5 & 0,2 & 0,8 & $8 \%$ \\
\hline 8 & 0,9 & 0,3 & 0,2 & $8 \%$ \\
\hline 9 & 0,4 & 0,5 & 0,6 & $7 \%$ \\
\hline 10 & 0,3 & 0,5 & 0,4 & $8 \%$ \\
\hline 11 & 0,1 & 0,4 & 0,0 & $21 \%$ \\
\hline 12 & 0,9 & 0,2 & 0,5 & $9 \%$ \\
\hline 13 & 0,3 & 0,8 & 0,5 & $7 \%$ \\
\hline 14 & 0,6 & 0,7 & 0,3 & $8 \%$ \\
\hline 15 & 0,9 & 0,8 & 0,6 & $11 \%$ \\
\hline 16 & 0,7 & 0,1 & 0,2 & $11 \%$ \\
\hline 17 & 0,4 & 0,4 & 0,8 & $7 \%$ \\
\hline 18 & 0,7 & 0,4 & 0,2 & $8 \%$ \\
\hline 19 & 0,9 & 0,6 & 0,3 & $9 \%$ \\
\hline 20 & 0,7 & 0,5 & 0,8 & $9 \%$ \\
\hline 21 & 0,9 & 0,8 & 0,3 & $9 \%$ \\
\hline 22 & 0,7 & 0,3 & 0,9 & $8 \%$ \\
\hline 23 & 0,4 & 0,7 & 0,7 & $7 \%$ \\
\hline 24 & 0,2 & 0,6 & 0,4 & $8 \%$ \\
\hline 25 & 0,6 & 0,7 & 0,1 & $7 \%$ \\
\hline 26 & 0,1 & 0,7 & 0,2 & $9 \%$ \\
\hline 27 & 0,6 & 0,1 & 0,7 & $9 \%$ \\
\hline 28 & 0,1 & 0,9 & 0,4 & $7 \%$ \\
\hline 29 & 0,9 & 0,5 & 0,1 & $8 \%$ \\
\hline 30 & 0,4 & 0,5 & 0,8 & $7 \%$ \\
\hline \multicolumn{4}{|c|}{ Average } & $9 \%$ \\
\hline
\end{tabular}

TABEL III

ACUAN DASAR AKURASI PREDIKSI

\begin{tabular}{|c|c|}
\hline Range MAPE & Keterangan \\
\hline$<10 \%$ & Model prediksi dikatakan sangat baik \\
\hline $10 \%-20 \%$ & Model prediksi dikatakan baik \\
\hline $20 \%-50 \%$ & Model prediksi dikatakan layak \\
\hline$>50 \%$ & Model prediksi dikatakan buruk \\
\hline
\end{tabular}

TABEL IV

Data Alfa Beta Gamma Dengan AKurasi SANGat BaIK

\begin{tabular}{|c|c|c|c|c|}
\hline No & Alfa & Beta & Gamma & MAPE \\
\hline 1 & 0,8 & 0,6 & 0,5 & $10 \%$ \\
\hline 2 & 0,5 & 0,2 & 0,2 & $9 \%$ \\
\hline 3 & 0,1 & 0,6 & 0,3 & $10 \%$ \\
\hline 4 & 0,8 & 0,4 & 0,6 & $9 \%$ \\
\hline 5 & 0,5 & 0,2 & 0,8 & $8 \%$ \\
\hline 6 & 0,9 & 0,3 & 0,2 & $8 \%$ \\
\hline 7 & 0,4 & 0,5 & 0,6 & $7 \%$ \\
\hline
\end{tabular}




\begin{tabular}{|c|c|c|c|c|}
\hline 8 & 0,3 & 0,5 & 0,4 & $8 \%$ \\
\hline 9 & 0,9 & 0,2 & 0,5 & $9 \%$ \\
\hline 10 & 0,3 & 0,8 & 0,5 & $7 \%$ \\
\hline 11 & 0,6 & 0,7 & 0,3 & $8 \%$ \\
\hline 12 & 0,4 & 0,4 & 0,8 & $7 \%$ \\
\hline 13 & 0,7 & 0,4 & 0,2 & $8 \%$ \\
\hline 14 & 0,9 & 0,6 & 0,3 & $9 \%$ \\
\hline 15 & 0,7 & 0,5 & 0,8 & $9 \%$ \\
\hline 16 & 0,9 & 0,8 & 0,3 & $9 \%$ \\
\hline 17 & 0,7 & 0,3 & 0,9 & $8 \%$ \\
\hline 18 & 0,4 & 0,7 & 0,7 & $7 \%$ \\
\hline 19 & 0,2 & 0,6 & 0,4 & $8 \%$ \\
\hline 20 & 0,6 & 0,7 & 0,1 & $7 \%$ \\
\hline 21 & 0,1 & 0,7 & 0,2 & $9 \%$ \\
\hline 22 & 0,6 & 0,1 & 0,7 & $9 \%$ \\
\hline 23 & 0,1 & 0,9 & 0,4 & $7 \%$ \\
\hline 24 & 0,9 & 0,5 & 0,1 & $8 \%$ \\
\hline 25 & 0,4 & 0,5 & 0,8 & $7 \%$ \\
\hline
\end{tabular}

TABEL V

Data Alfa Beta Gamma Dengan AKurasi Sangat Baik

\begin{tabular}{|c|c|c|c|c|c|c|}
\hline \multirow{2}{*}{$\begin{array}{c}\text { \{Alfa, } \\
\text { Beta, } \\
\text { Gamm } \\
\text { a\} }\end{array}$} & \multicolumn{2}{|c|}{$\begin{array}{c}\text { Bulan } 11 \text { tahun } \\
2020\end{array}$} & \multicolumn{2}{|c|}{$\begin{array}{c}\text { Bulan } 12 \text { tahun } \\
2020\end{array}$} & \multicolumn{2}{|c|}{$\begin{array}{c}\text { Bulan } 1 \text { tahun } \\
2021\end{array}$} \\
\hline & $\begin{array}{c}\text { Angka } \\
\text { Prediks } \\
\text { i }\end{array}$ & $\begin{array}{l}\text { MAP } \\
\text { E }\end{array}$ & $\begin{array}{l}\text { Angka } \\
\text { Prediksi }\end{array}$ & $\begin{array}{c}\text { MAP } \\
\text { E }\end{array}$ & $\begin{array}{l}\text { Angka } \\
\text { Prediksi }\end{array}$ & $\begin{array}{c}\text { MAP } \\
\text { E }\end{array}$ \\
\hline $\begin{array}{l}\{0.4, \\
0.5, \\
0.6\}\end{array}$ & 63291 & $7 \%$ & 27409 & $6 \%$ & 52627 & $6 \%$ \\
\hline $\begin{array}{l}\{0.3, \\
0.8, \\
0.5\} \\
\end{array}$ & 75135 & $7 \%$ & 38000 & $7 \%$ & 62885 & $6 \%$ \\
\hline $\begin{array}{l}\{0.4 \\
0.4 \\
0.8\} \\
\end{array}$ & 92065 & $7 \%$ & 25964 & $6 \%$ & 53775 & $6 \%$ \\
\hline
\end{tabular}

Berdasarkan tabel 2 di dapatkan sejumlah hasil MAPE dengan rentang nilai akurasi paling kecil adalah 7\%, dan yang paling besar $24 \%$, dimana rata - rata dari pengujian 30 kali Alfa Beta Gamma secara acak adalah 9\%. Dasar range nilai MAPE yang dijadikan acuan standar model prediksi baik atau tidak sendiri [11] ditunjukkan pada tabel 3.

Melihat tabel 3, dapat dikatakan model prediksi yang dikembangkan pada penelitian ini ada pada rentang sangat baik, baik dan layak. Merujuk pada tabel 2, didapatkan sejumlah data alfa, beta dan gamma yang memiliki akurasi MAPE sangat baik, ditunjukkan pada tabel 4 .

Merujuk pada tabel 4, peneliti akan menggunakan data tersebut untuk memprediksi 3 bulan periode ke depan trend turis pariwisata Jatim Park Batu dengan mengambil data Alfa Beta dan Gamma dengan nilai MAPE paling rendah seperti: $\{0.4,0.5,0.6\}$ yang memiliki nilai MAPE $7 \%$ (tabel 4 no 7 ), $\{0.3,0.8,0.5\}$ yang memiliki nilai MAPE juga $7 \%$ (tabel 4 no 10) dan seterusnya.

Berdasarkan tabel 4 peneliti sudah mendapatkan sejumlah data nilai Alfa Beta dan Gamma yang dikatakan memiliki nilai MAPE sangat baik, seperti $\{0.4,0.5,0.6\}$ yang memiliki nilai MAPE 7\%. Maka peneliti menggunakan data tersebut untuk memprediksi 3 bulan periode ke depan, sehingga didapatkan 3 record data angka prediksi dengan trend naik atau turun. Diambil 3 record data Alfa Beta Gamma untuk mendapatkan angka prediksi 3 bulan periode ke depan untuk mendapatkan trendnya, yaitu parameter Alfa Beta Gamma $\{0.4,0.5,0.6\},\{0.3,0.8,0.5\}$ dan $\{0.4,0.4,0.8\}$. Hasil dari prediksi, akurasi dan trend dari 3 pasang parameter Alfa Beta Gamma ditunjukkan pada tabel 5 .

Berdasarkan tabel 4, didapatkan sejumlah data angka prediksi dengan rata - rata MAPE semuanya $6.4 \%$. Artinya model prediksi yang digunakan untuk mengetahui trend data turis pariwisata Jatim Park Batu ini sangat baik. Visualisasi hasil data untuk menggambarkan trend tabel 5 pada masing masing tiap parameter Alfa Beta Gamma ditunjukkan pada grafik gambar 4 .

Terlihat pada gambar 4 terdapat tren penurunan dari bulan November 2020 ke Desember 2020, kemudian meningkat pada bulan Januari 2021. Peningkatan ini terjadi meskipun tidak setinggi pada bulan November 2020

Berdasarkan gambar 4 dapat disimpulkan bahwa prediksi tren yang terjadi pada data historis turis pariwisata Jatim Park Batu adalah trend naik, dengan memperhatikan pola keseluruhan data 3 bulan periode terakhir yaitu pada bulan November dan Desember 2020 dan Januari 2021.

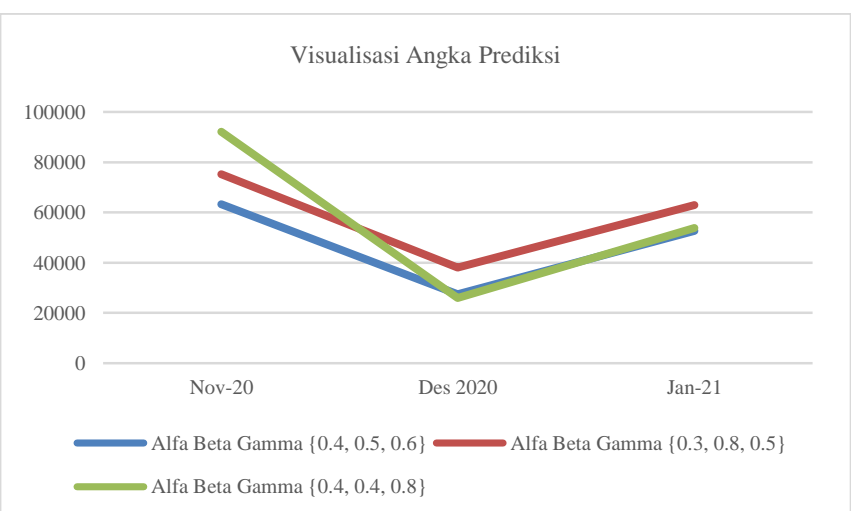

Gambar 4. Visualisasi grafik trend parameter Alfa Beta Gamma dengan mencoba kombinasi parameter yang terbaik

\section{KESIMPULAN}

Berdasarkan pengujian dan analisis dari implementasi algoritma Triple Exponential Smoothing - Holt Winters pada dataset turis pariwisata Jatim Park Batu, didapatkan hasil bahwa : Hasil pengujian 30 kali algoritma Triple Exponential Smoothing - Holt Winters dengan pembangkitan secara acak parameter Alfa Beta dan Gamma, didapatkan rata - rata MAPE 9\%, dimana secara acuan dasar referensi, model tsb sangat baik, rentang angka MAPE terkecil adalah 7\%, sedangkan terbesar adalah $24 \%$, artinya secara acuan dasar referensi, model tersebut dikatakan sangat baik, baik dan layak, hasil prediksi untuk visualisasi data 3 bulan periode terakhir didapatkan rata - rata keseluruhan MAPE 6.4\%, dimana secara acuan dasar referensi, model tsb sangat baik. Berdasarkan analisis terhadap visualisasi grafik hasil prediksi 3 bulan periode terakhir yang didapat pada gambar 4 maka 
tren menunjukkan kenaikan, meskipun tidak setinggi bulan ke 11 tahun 2020.

Saran atau masukan yang diperlukan bagi penelitian selanjutnya yaitu, diperlukan sebuah mekanisme atau metode untuk mengoptimalkan algoritma Triple Exponential Smoothing - Holt Winters, agar tidak perlu melakukan mekanisme pencarian parameter yang memiliki akurasi yang baik.

\section{DAFTAR PUSTAKA}

[1] "Kementrian Pariwisata dan Ekonomi Kreatif / Badan Pariwisata dan Ekonomi Kreatif Republik Indonesia," Pemerintah Indonesia, 2020 [Online]. Available: kemenparekraf.go.id/. [Accessed Januari 2020].

[2] S. Oktarianisa, "CNBC Indonesia," CNBC Indonesia, 14 July 2020. [Online]. Available: https://www.cnbcindonesia.com/news/20200714102931-4172483/resesi-minus-41-ekonomi-singapura-terparah-sejak-merdeka

[3] Sugiyanto \& Rinci K.H, "Implementasi Metode Triple Exponential Smoothing Dalam Peramalan Penjualan Pulsa Elektrik", SCAN Jurnal Teknologi Informasi dan Komunikasi, vol XI no 1 Februari 2016

[4] Ratih Y.H, "Implementasi Metode Triple Exponential Smoothing Untuk Prediksi Penjualan Alat Kesehatan", Evolusi: Jurnal Sains dan Manajemen. vol 8 no 1 Maret 2020
[5] Bossarito Putro, M. Tanzil Furqon \& Satrio H.W, "Prediksi Jumlah Kebutuhan Pemakaian Air Menggunakan Metode Exponential Smoothing (Studi Kasus: PDAM Kota Malang)", Jurnal Pengembangan Teknologi Informasi dan Ilmu Komputer. vol 2 pp 4679-4686 no 11 November 2018

[6] R.Laksmana, E.Santoso, and B.Rahayudi, "Prediksi Penjualan Roti Menggunakan Metode Exponential Smoothing(Studi Kasus : Harum Bakery)," Jurnal Pengembangan Teknologi Informasi dan Ilmu Komputer, vol. 3, no. 5, p. 4933, 2019.

[7] B. D. S. B. R. AmaliahGusfadilah, "Implementasi Metode Exponential SmoothingUntuk Prediksi Bobot Kargo Bulanan Di Bandara Internasional I Gusti Ngurah Rai," Jurnal Pengembangan Teknologi Informasi dan Ilmu Komputer, vol. 3, no. 2, pp. 1875-1882, 2019.

[8] S. Alfarisi, "Sistem Prediksi Penjualan Gamis Toko Qitaz," Journal of Applied Business and Economics, vol. 4, no. 1, pp. 80-95, 2017.

[9] J. Nangi, S. H. Indrianti, and B. Pramono, "Peramalan persediaan obat menggunakan metode Triple Exponential Smoothing (Tes) (studi kasus : Instalasi Farmasi rsud kab. Muna)," semanTIK, vol. 4, no. 1, pp. 135-142, 2018.

[10] K. D. Hartomo, S. Y. Prasetyo, and R. A. Suharjo, "Prediksi Stok dan Pengaturan Tata Letak Barang Menggunakan Kombinasi Algoritma Triple Exponential Smoothing dan FP-Growth,” Jurnal teknologi informasi dan ilmu komputer, vol. 7, no. 5, p. 869, 2020.

[11] M. A. Maricar, "Analisa Perbandingan Nilai Akurasi Moving Average dan Exponential Smoothing untuk Sistem Peramalan Pendapatan pada Perusahaan XYZ”, jsi, vol. 13, no. 2, pp. 36-45, May 2019. 